\title{
Descolonialidade e linguagem na educação: transgredindo os limites da língua na África do Sul
}

\author{
Anderson Lucas Macedo ${ }^{1}$ \\ Gabriela Freire $^{2}$
}

Resumo: Este capítulo se baseia na teorização da descolonialidade para mostrar como a língua(gem) na educação política na África do Sul continua a ser moldada por uma "matriz colonial de poder" (MIGNOLO, 2009). Isso leva ao silenciamento das crianças africanas e sua exclusão de uma educação de qualidade. O capítulo argumenta que transgredir socialmente limites de língua(gem) construídos e provocar ideologias linguísticas monolíngues é central para o reposicionamento da língua como um recurso de aprendizagem na escolaridade sulafricana. A primeira parte do capítulo analisa ideologias linguísticas presentes nas políticas e currículos educacionais na África do Sul. A análise mostrará como anglonormatividade (a expectativa de que as pessoas são ou devem ser proficientes em inglês e são consideradas deficientes, até mesmo desviantes, quando não são) e as ideologias monolingualistas moldam a implementação atual da política linguística nas escolas sul-africanas. A segunda parte do capítulo apresenta um estudo de caso da língua descolonial e a pedagogia do letramento que transgride as fronteiras linguísticas permitindo que as crianças utilizem seus repertórios linguísticos como recursos para uma construção de sentido.

Palavras-chave: Anglonormatividade. Ideologia Linguística. Translinguagem. África do Sul.

\section{Introdução $0^{3}$}

uma das experiências mais humilhantes era ser fla-

1 Formado em Letras pela UFRJ e Mestre em Estudos da Linguagem pela UFF. Atualmente, ele é doutorando também em Estudos da Linguagem pela mesma Universidade - pesquisador bolsista do CNPq.

2 Possui Graduação em Letras - Português/Francês (UFF/2013) e mestrado em Estudos de Linguagem (UFF/2015), na área de linguística aplicada. Atualmente é doutoranda em "História, política e contato linguístico" na Universidade Federal Fluminense (RJ/Brasil), bolsista CNPq e faz parte do Grupo de Pesquisa Interinstitucional da América Francófona (PIAF).

3 Todas as notas de rodapé foram incluídas pelos tradutores visando a esclarecer alguns pontos específicos, especialmente no tange a termos políticos e pedagógicos. O texto original, contudo, também apresenta notas, que se encontram no final do artigo. As notas originais estão identificadas com colchetes. 
grado falando gikuyu nas proximidades da escola. $\mathrm{O}$ culpado receberia uma punição física - de três a cinco golpes de bengala nas nádegas descobertas - ou ser obrigado a carregar uma placa de metal em volta do pescoço com inscrições como EU SOU ESTÚPIDO ou EU SOU UM BURRO. Às vezes, os culpados eram multados em dinheiro que mal podiam pagar (...). (NGŨGĨ WA THIONG’O, 1986, p. 11-12)

Eu me lembro de ser pega falando espanhol no recreio - o que era motivo para três pancadas no meio da mão com uma régua afiada. Eu me lembro de ser mandada para o canto da sala de aula por "responder" à professora de inglês quando tudo o que eu estava tentando fazer era ensinar a ela como pronunciar meu nome ${ }^{4}$. (ANZALDUA, 1987, p. 75)

... não podemos falar nossa própria língua materna. Isso é compreensível durante o horário de aula, mas durante os intervalos nós sentamos com medo de que algum professor nos pegue falando a nossa língua. (Aluna de Sans Souci Girls citada em Cape Times, 16 de setembro de 2016)

s citações acima chamam nossa atenção para as experiências embaraçosas de ser censurado por usar outras línguas, além do inglês, em sistemas de ensino pós-coloniais. Enquanto os dois primeiros relatos refletem experiências marcantes em escolas no Quênia colonial e nos Estados Unidos, respectivamente, o terceiro relato de uma aluna que não pode falar sua própria língua é atual. A violência física e/ou epistêmica que a autora queniana Ngũgĩ wa Thiong’o e a autora chicana Gloria

4 Cadernos de Letras da UFF - Dossiê: Difusão da língua portuguesa, nº 39, p. 297-309, 2009. 
Anzaldua relataram atraem nosso olhar de forma tão poderosa para fato dessa situação continuar a ser reproduzida no sistema educacional sulafricano, mesmo após 30 anos. Ainda mais preocupante, nas palavras da estudante de Ensino Médio de uma escola na Cidade do Cabo, é o fato de ela não poder usar sua 'língua materna' em sala de aula, mas apenas fora do ambiente escolar. A subjugação contínua das práticas linguísticas de alunos pertencentes a grupos não-dominantes na educação é possibilitada por poderosas ideologias linguísticas monolíngues ou monoglóssicas, bem como anglonormativas. Enquanto as ideologias monoglóssicas promovem o mito de que a criança típica é um falante monolíngue de uma única língua "padrão", a Anglonormatividade se refere à expectativa de que as pessoas sejam e devam ser proficientes em Inglês, caso contrário, elas serão consideradas deficientes, ou mesmo desviantes. (MCKINNEY, 2017) [1].

Eu defendo que tanto o mito do monolinguismo quanto o domínio da língua inglesa são produtos da colonialidade, definidos por MaldonadoTorres (2007) como os "padrões de poder duradouros que surgiram como resultado do colonialismo, mas que definem a cultura, o trabalho, relações intersubjetivas e produção de conhecimento muito além dos limites estritos das administrações coloniais" (MALDONADO-TORRES, 2007, p.243). Em suma, colonialidade é aquilo que 'sobrevive ao colonialismo' (MALDONADO-TORRES, 2007). O poder da colonialidade de moldar o que se considera por práticas linguísticas legítimas na educação sulafricana, bem como a maneira como podemos silenciar as ideologias linguísticas coloniais que orientam a linguagem na educação, são uma preocupação central para este capítulo. Ngũgĩ wa Thiongo argumentou que "língua era o veículo mais importante através do qual aquele poder [colonial] fascinava e mantinha a alma prisioneira. A munição era o meio de subjugação física. A língua era o meio de subjugação espiritual” (1986, p.3). Pode-se argumentar que a contínua aceitação de um sistema escolar que seguidamente reprova crianças falantes da língua africana na África 
do Sul é um legado de tal subjugação espiritual. Na opinião de Ngugi, o colonialismo tinha:

o efeito de uma bomba cultural [...] aniquilando [...] a crença de um povo em seus nomes, em suas línguas, em seu ambiente, em sua herança de luta, em sua unidade, em suas capacidades e, finalmente, em si mesmo. (1986, p.3)

Hoje, os pais sul-africanos aceitam amplamente o mito de que as línguas africanas não podem ser usadas na aprendizagem e produção de conhecimento e que qualquer tipo de educação em inglês é superior. Aceitamos que nossos filhos devem fazer a transição para o inglês como língua de aprendizagem e ensino o mais rápido possível, pelo menos a partir do $4^{\circ}$ ano; as crianças do $1^{\circ}$ ao $3^{\circ}$ ano de escola devem ter algumas horas de exposição ao aprendizado da língua inglesa e devem seguir o mesmo currículo, usar os mesmos livros-texto monolíngues em inglês e ter as mesmas avaliações monolíngues em inglês que seus colegas de língua do lar. ${ }^{5}$ Grande parte dos professores aceitam que devem esconder seu bi/multilinguismo dos funcionários da educação e ver suas práticas inovadoras de linguagem bilíngue como insatisfatórias.

Com base na colonialidade e nas ideologias linguísticas, neste capítulo trarei uma breve visão geral e uma análise da perspectiva da colonialidade e das ideologias linguísticas na atual política educacional na África do Sul. Quero prestar atenção principalmente à concepção colonial de língua que orienta essa política e sua implementação. Argumentarei que, na formulação de políticas educacionais e, no caso do currículo sul-africano prescrito e suas revisões, um habitus monolíngue 5 A autora utiliza neste texto os termos "mother tongue", que traduzimos por língua materna, e "home language"
que traduzimos literalmente por "língua do lar". Essas duas expressões estão presentes em diversas partes do artigo. 
orientou a abordagem de língua e de alfabetização. "Quem” influencia as decisões curriculares importa, especialmente aquelas em termos de seus próprios recursos linguísticos, histórias e classes sociais, bem como os posicionamentos raciais. $\mathrm{Na}$ minha perspectiva, a falta de reconhecimento dos recursos linguísticos das crianças (principalmente negras), devido ao domínio do inglês e de ideologias monolíngues na África do Sul e em outros contextos pós-coloniais, é uma forma de racismo e uma das formas mais perniciosas em que a colonialidade continua a moldar o sistema escolar e seus resultados profundamente desiguais. Após esta discussão política, apresentarei um estudo de caso de pedagogia de linguagem e de letramento que parte do multilinguismo como norma e que assume uma abordagem bilíngue dinâmica. $\mathrm{O}$ estudo de caso oferece um exemplo de abordagem pedagógica que desenvolve usuários eficazes de recursos linguísticos e de letramento em um espaço de translinguagem estabelecido (GARCÍA \& LI WEI, 2014).

\section{Linguagem pós-apartheid na política educacional na África do}

Em 1997, o primeiro governo democrático da África do Sul inaugurou uma política educacional muito celebrada. Seguindo a orientação da constituição da África do Sul de 1996, que reconhecia 11 línguas oficiais, a política afirmava claramente seu objetivo de "promover o multilinguismo, o desenvolvimento das línguas oficiais e o respeito por todas as línguas usadas no país" (DoE, 1997, Preâmbulo 1). O princípio subjacente de "bi/ multilinguismo aditivo" definido como "manter a(s) língua(s) materna(s) e também prover acesso e aquisição efetiva de língua(s) adicional(is)" foi apresentado como "a orientação normal de nossa política linguística na educação" (Preâmbulo 5). No entanto, mesmo no idealismo da política pósapartheid inicial, a ideia de "manter" a língua do lar enquanto se aprendem 
outras, e não desenvolvê-la e estender seu conhecimento, está presente. Há também a reprodução da ideia de línguas nomeadas, separadas em silos sem o reconhecimento das variações dentro delas, ou das potenciais lacunas entre as línguas elencadas pela constituição e o uso cotidiano que envolve elementos de mais de uma destas línguas, frequentemente múltiplas em contextos urbanos. Embora a prática amplamente utilizada de mover-se pelas línguas nomeadas no discurso falado, muitas vezes chamada de codewitching na literatura, seja comum em salas de aula onde há uma incompatibilidade entre a língua materna dos professores e dos alunos e a língua de aprendizagem e ensino, o fenômeno não é referido, nem como uma norma bi/multilíngue, nem como uma estratégia potencial na política linguística.

Apesar do ethos 'multilíngue’ do preâmbulo da política de 1997, o que foi legalmente exigido era apenas que os alunos estudassem e passassem em uma língua nos primeiros dois anos de escola e outra língua como 'primeira língua adicional' ou segunda língua, a partir do terceiro ano. Embora exista uma literatura extensa e valiosa sobre a falta de implementação de uma política multilíngue nas escolas sul-africanas [2], falta nesta pesquisa a consideração de como a própria língua é conceituada na política, em outras palavras, as ideologias linguísticas presentes na política. A ideologia mais significativa presente tanto no apartheid quanto na política linguística pós-apartheid e sua implementação parte da concepção das línguas como entidades estáveis, delimitadas e claramente diferenciadas umas das outras, ou seja, uma concepção monoglóssica de linguagem. Assim, as ideias sobre o que as escolas devem fazer na implementação da política linguística são profundamente moldadas por ideologias monoglotas que constroem a imagem do aluno ideal ou da criança normal, não como alguém multilíngue, mas monolíngue, e o uso simultâneo de recursos linguísticos multilíngues (ou cruzamento de fronteiras linguísticas) é tomado como problemático e desviante. Existe, portanto, um segmento significativo 
nas políticas educacionais no apartheid e no pós-apartheid, bem como as concepções do que é língua e do que se entende (ou não se entende) por competência linguística e capital. Isso significa que, na prática, as mesmas crianças que eram racial e linguisticamente privilegiadas durante a escolarização no apartheid, uma minoria de falantes de variedades tradicionais de inglês e afrikaans, continuam a ser privilegiadas. Embora a política enfatize o "multilinguismo" como norma, ela prescreve práticas monolíngues em uma única língua materna (primeira língua) e uma única segunda língua (denominada Primeira Língua Adicional, PLA ${ }^{6}$ ). Isso mantém limites estritos entre "línguas nomeadas", apesar da natureza altamente heteroglóssica das práticas linguísticas na vida diária dentro e fora das escolas (por exemplo, MCKINNEY, 2014; PROBYN, 2015).

\section{Nova política linguística pela porta dos fundos}

A Declaração de política de currículo e avaliação ${ }^{7}$, introduzida nas escolas em 2010 e ainda em vigor, torna obrigatório que as crianças tenham e sejam aprovadas em duas línguas como disciplinas a partir da $1^{a}$ série (e não a partir da $3^{\text {a }}$ série, conforme previamente determinado). Essas duas línguas são, usando a terminologia do currículo, uma "língua do lar" e uma "Primeira Língua Adicional". Este documento em vigência introduz uma nova linguagem na política educacional, substituindo o documento de 1997. Embora agora exista a necessidade de uma inclusão antecipada de uma língua adicional e de uma expansão do tempo investido nessa língua como disciplina, não há, no entanto, nenhuma mudança na concepção

\footnotetext{
6 No texto original, First Additional Language (FAL).

7 No original, Curriculum and Assessment Policy Statements' (CAPS)

8 No original, home language.

9 No original, First Additional Language
} 
de língua, ou nas ideologias linguísticas, informadas no currículo. Essa mudança na política linguística na educação, realizada indiretamente, foi acompanhada por um documento no site do Departamento Nacional de Educação Básica, intitulado "Perguntas mais frequentes sobre Língua de Aprendizagem e Ensino ${ }^{10 "}$ (DoBE, 2010). Embora não seja uma política oficial, o documento de uma página produziu respostas confiáveis a questões específicas sobre a política linguística para as escolas do ponto de vista governamental e apoiou-se em ideologias linguísticas muito claras. Eu gostaria de dar foco aos últimos cinco pontos que respondem à pergunta: 'É correto que os alunos da fase de base ${ }^{11}$ tenham agora que ter sua língua do lar como língua de ensino e aprendizagem mais uma língua adicional? As escolas têm que oferecer mais de duas línguas?'

( $5^{\circ}$ ponto) Os alunos que são ensinados na sua língua do lar têm um desempenho melhor do que os alunos são ensinados em uma segunda língua ou língua estrangeira. Ao mesmo tempo, os alunos aprendem inglês como disciplina para desenvolver competências básicas nessa língua e, assim, aumentar sua utilidade enquanto língua de aprendizagem e ensino mais tarde (a partir da $4^{\text {a }}$ série). (DoBE, 2010).

Embora nem a política de 1997 nem o currículo atual da Declaração de política de currículo e avaliação estabeleçam oficialmente que as crianças devem mudar da instrução língua do lar para o inglês, após os primeiros três anos escolares, ou seja, na $4^{\mathrm{a}}$ série, esse modelo de saída precoce do bilinguismo (WALTER, 2008) é uma política amplamente difundida nas escolas primárias (PROBYN, 2005; Departamento de Educação Básica, 2010). Na lista de marcadores, entretanto, vemos em algumas palavras

\footnotetext{
10 No original, Frequently asked questions about LOLT/Language of Learning and Teaching

11 No original, foundation phase learners
} 
escritas entre parênteses no final do ponto 5, "a partir da 4 série" - que é de fato uma prática esperada. Ademais, os departamentos provinciais de educação não fornecem nenhum tipo de livros didáticos, avaliações ou apoio de aprendizagem para nenhuma das 9 línguas indígenas africanas oficiais. A ideia de que se pode mudar a língua de aprendizagem e ensino em uma sala de aula, de um dia para o outro (ou seja, do último dia da $3^{\text {a }}$ série ao primeiro dia do novo ano da $4^{\text {a }}$ série), é questionável e provavelmente nunca ocorrerá dessa forma na prática, exceto nos casos em que o professor da $4^{\text {a }}$ série tenha apenas competência monolíngue em inglês (muito incomum nas escolas onde uma língua africana é a língua do lar e a língua de aprendizagem e ensino nos anos 1-3). Essa noção de mudança repentina na língua de ensino e aprendizagem, portanto, só faz sentido se alguém estiver trabalhando com uma ideologia monoglóssica, como no caso de instituições claramente delimitadas. Além disso, a ideia de que alguém pode aprender uma língua através da exposição de algumas horas semanais numa disciplina escolar, a fim de ser capaz de aprender exclusivamente por meio dessa língua, depende da "construção social da linguagem, em geral, como um objeto mental individual estável e sem contexto" (BLOMMAERT, 2006, p. 512). Além disso, o currículo em inglês como disciplina não foi projetado para ensinar aos alunos os usos necessários dessa língua para outras áreas do currículo, como matemática ou ciências sociais.

Tendo isso em mente, podemos nos perguntar como as duas afirmações podem ser feitas paralelamente, como no quinto item citado acima - primeiro os alunos "têm um desempenho melhor" quando ensinados em sua língua do lar e, segundo, os alunos devem aprender inglês simultaneamente, mas separadamente em inglês como uma disciplina "para aumentar sua utilidade como língua de aprendizagem e ensino ... (a partir da $4^{\mathrm{a}}$ série)." Também é indicado que os alunos aprendam "inglês como disciplina para desenvolver competências linguísticas básicas”, mas 
sua "competência linguística básica" é insuficiente quando a língua é a ferramenta mais significativa para uma criança acessar o currículo. Não há dúvida de que os pais de classe média de crianças falantes de inglês e afrikaans, que começaram a vida escolar nessas línguas nomeadas e que continuaram a receber educação nessas línguas, jamais aceitarão que seus filhos passem para a 4 a série com apenas "competência básica” dessas línguas de instrução. Numa saída antecipada e numa repentina transição para um modelo bilíngue [3], tal como está amplamente implementada na África do Sul e em diversos outros contextos pós-coloniais, a maioria das crianças serão privadas da oportunidade de usarem seus repertórios linguísticos como fonte de produção de sentido. É difícil não chegar à conclusão de que essas crianças não tenham uma expectativa de se tornarem exitosas produtoras de significado e que possam se envolver com o conhecimento de modo crítico e criativo.

Os dilemas discutidos acima são familiares a diversos contextos diferentes da África do Sul, onde os alunos são multilíngues, mas a política e os currículos são formados por orientações monoglóssicas. Monolingualismo paralelo em vez de heteroglossia [4] caracteriza a política educacional multilíngue globalmente, mas há pouco reconhecimento disso (veja CREESE \& BLACKLEDGE, 2010; MARTIN-JONES, 2007). As ideologias monoglóssicas relacionadas à política linguística e currículo, provenientes do colonialismo, são, portanto, um fator central na recontextualização dos recursos linguísticos das crianças africanas como problemas e deficiências em seu ingresso na escola. Com base nessa orientação monoglóssica, apenas os usuários de uma única língua do lar podem ser visualizados como aprendizes ideais ou normativos em tal política. E os monolíngues em inglês, cuja língua do lar corresponda à língua de aprendizagem e ensino, são considerados os alunos "ideais", causando o mínimo de "problemas" para as escolas. 


\section{De Monoglossia a Heteroglossia: Instrução em língua materna e}

bilinguismo dinâmico

A crítica à prática de tentar educar as crianças em países póscoloniais por meio de uma língua estrangeira não é nova. Mas essa crítica é geralmente encontrada no debate sobre os méritos da língua do lar como meio de instrução versus língua estrangeira/inglês como meio de instrução. Esse debate, que opõe claramente uma língua a outra, não é construtivo em um mundo onde o multilinguismo é a norma e onde as práticas linguísticas cotidianas são heteroglóssicas, constantemente transgredindo as fronteiras da "língua" socialmente construída. A noção de "língua materna" ou de uma única língua dominante em casa também é problemática.

No louvável interesse de acesso à educação de qualidade, a UNESCO defende a língua do lar como meio de ensino para todas as crianças e como requisito básico para uma educação de qualidade desde 1953 (UNESCO, 1953, 2003). Mas, como Ag e Jørgensen (2013) apontaram, "a opinião de que cada pessoa deve ter uma relação próxima com uma 'língua', quase invariavelmente a 'língua materna' da pessoa" é também uma consequência de uma ideologia monoglóssica (2013, p.527, ver também MAKONI \& MEINHOF, 2003; SEBBA, 2000; WINKLER, 1997). Em outras palavras, a noção de língua materna e a ideia de que todas as crianças/ adultos possuem uma única língua dominante que é aprendida desde o nascimento, (re)produz a criança monolíngue como norma. A noção de língua materna também se alinha com a língua vista como objeto e invoca uma única língua padrão, negando a natureza heteroglóssica da linguagem e as múltiplas variedades de línguas nomeadas. Relacionada a isso está a preocupação de que para muitas crianças africanas em contextos urbanos, caracterizados historicamente pela migração, os vernáculos urbanos variam muito da forma padrão das línguas mencionadas pela constituição sul-africana. (MAKONI et al., 2010) Nesses casos, é o próprio conceito de 
língua materna que pode negar a esses alunos o acesso à aprendizagem por meio do repertório e das práticas linguísticas que lhes são mais familiares e que levam para a escola formal.

Outra preocupação é com o uso politizado, historicamente, de ensino de língua materna com o objetivo de impedir o acesso ao inglês nos contextos coloniais britânicos. De Klerk (2002) mostra a relação histórica entre a educação em língua materna e a educação Bantu, vista como inferior, imposta pelo apartheid. A educação Bantu estabeleceu o meio de instrução em língua materna, inicialmente durante a escolaridade primária (até a $8^{\text {a }}$ série) e depois para a $4^{\mathrm{a}}$ série, com uma transição repentina para o inglês ou afrikaans comolíngua de instrução. A educação na língua materna, portanto, passou a ser associada à restrição do acesso dos alunos ao inglês [5]. Como Makoni (1999) apontou, o legado da invenção colonial de línguas africanas na África do Sul vive fortemente por meio dos direitos linguísticos pósapartheid na constituição. Enquanto tenta minar o domínio do afrikaans e do inglês, por meio da inclusão de nove línguas indígenas como oficiais, a cláusula dá continuidade às categorias etnolinguísticas usadas para dividir e governar os povos africanos durante o apartheid. Essas línguas nomeadas oficiais informam e restringem o que é considerado verdadeiramente uma língua que pode ser usada e estudada como disciplina escolar (MAKONI, 1999, 2003). No entanto, as construções coloniais de línguas indígenas, em muitos casos, foram sedimentadas nos repertórios linguísticos das pessoas. E, apesar de sua construção colonial, muitas pessoas têm fortes apegos ou investimentos nas línguas oficiais sul-africanas.

\section{De Monoglossia a Heteroglossia: Princípios para o bilinguísmo} dinâmico na prática

Tendo apresentado uma análise das ideologias monoglóssicas que sustentam a língua na política educacional e sua implementação em um 
contexto pós-colonial, assim como as limitações da 'língua materna' apenas na educação, eu gostaria agora de defender uma concepção alternativa de linguagem e pedagogias de letramento que visam desvincular-se da colonialidade. Essa pedagogia parte da heteroglossia como norma e reposiciona os alunos de origens não-dominantes como alunos habilidosos e legítimos. Isto tem como objetivo interromper a abordagem monolíngue dominante no ensino de línguas e, especificamente, frear a anglonormatividade, bem como interromper os limites que são construídos ou os limites entre as línguas nomeadas. Ou seja, eles interrompem a expectativa de que todos os alunos serão proficientes e farão uso exclusivo de uma variedade particular de prestígio do inglês padrão, bem como a expectativa de que apenas uma língua "pura" seja usada em uma determinada atividade e espaço. $\mathrm{Na}$ minha opinião, as pedagogias que trabalham para mudar o posicionamento do déficit de estudantes africanos e outros não-dominantes e seus recursos linguísticos precisam incluir pelo menos duas orientações:

- em primeiro lugar, um foco na relação entre língua e poder, e em especial nas línguas (além do inglês padrão e outras consideradas mais convencionais) que são marginalizadas nas aulas de língua e alfabetização bem como no sistema escolar de um modo mais amplo (Consciência Crítica da Linguagem);

- e, em segundo lugar, permitir que os alunos utilizem livre e criativamente seus repertórios linguísticos e multimodais completos para aprender, não apenas em aulas de línguas e alfabetização, mas em todo o currículo.

Em relação ao primeiro foco, língua e poder, precisamos envolver estudantes e professores a desenvolverem um conceito de língua(s), ideologias linguísticas e como essa reflexão conceitual pode beneficiar 
alguns e prejudicar outros (por exemplo, por meio de perfis linguísticos). Defendo envolver deliberadamente professores e estudantes em uma consciência linguística crítica a fim de combater ideologias que sustentam a anglonormatividade e a monoglossia. Além disso, permitir que os alunos usem plenamente seus repertórios linguísticos e expandir o que é considerado uso linguístico legítimo nas escolas; o segundo foco, demandará uma mudança nas ideologias linguísticas que são hegemônicas nas escolas, nas políticas educacionais e nos currículos escolares. As pedagogias linguísticas transgressoras levarão a sério esses dois focos. No entanto, as ideologias anglonormativas podem ser combatidas por meio de práticas de linguagem heteroglóssicas e discursos heteroglóssicos sobre linguagem. Isso ocorre porque o uso de recursos linguísticos não-ingleses e não-padrão / convencionais na sala de aula, por si só, legitima e aumenta o status desses recursos. Assim, o combate à anglonormatividade pode acontecer explicitamente, por meio do trabalho de conscientização crítica da linguagem que se opõe às ideologias hegemônicas da linguagem, e implicitamente, tornando visível, abrangendo e possibilitando o uso dos repertórios linguísticos dos alunos.

Um conceito heteroglóssico, que recentemente ganhou força em contextos pedagógicos de crescente diversidade linguística na América do Norte e no Reino Unido, é o de translinguagem. Em contraste com as ideologias que promovem o monolinguismo como normativo e as línguas como objetos claramente limitados, o conceito de translinguagem procede da linguagem multilíngue como norma (BLACKLEDGE \& CREESE, 2017; GARCÍA, 2009; GARCÍA \& LI WEI, 2014; MAKALELA, 2015). A translinguagem tem sido definida de várias maneiras enfatizando a descrição de práticas comunicativas, envolvendo uma gama de recursos semióticos e linguísticos, dimensão ideológica do rompimento do entendimento da linguagem como algo monoglóssico e monomodal. Blackledge e Creese (2017) também destacam as maneiras pelas quais as pessoas 'colocam em 
contato diferentes biografias, histórias e origens linguísticas' à medida que traduzem uma língua. Em nossa própria abordagem da translinguagem em contextos pedagógicos da África do Sul (por exemplo, GUZULA et al., 2016), meu foco tem sido na translinguagem:

- como uma prática comunicativa normativa entre bi / multilíngues;

- como uma posição ideológica que resiste à noção de línguas nomeadas como objetos autônomos e limitados; e

- como um termo descritivo que incorpora modos semióticos além da língua.

\section{Estudo de caso: Desenvolvimento da biliteracia entre crianças de}

\section{0 a 12 anos na zona rural do Cabo Oriental, África do Sul}

O estudo de caso que aqui apresento relata a iniciativa dos acampamentos de produção escrita Phemba Mfundi (Aprendizes do fogo) do Nelson Mandela Institute for Rural Education and Development (NMI), com sede na Universidade de Fort Hare, no Cabo Oriental, África do Sul. Esta iniciativa já existe há algum tempo e minhas descrições são retiradas do terceiro acampamento de produção escrita do ano de 2014, que foi realizado no complexo do Museu Nelson Mandela, local de nascimento de Madiba, Qunu, e do qual participei. Os acampamentos de produção escrita foram iniciados como oficinas de demonstração para professores em escolas rurais isoladas, que reclamaram que as estratégias a que foram expostos durante as oficinas de treinamento de professores em serviço não eram viáveis em suas próprias configurações de sala de aula e com seus alunos em particular. A equipe do NMI estava, portanto, desafiando explicitamente o déficit de ensino das crianças de zonas rurais nas escolas com o objetivo de mostrar aos professores o que essas crianças eram 
capazes de realizar. Os acampamentos, que acontecem ao longo de 2-3 dias, são organizados em torno de três feriados no calendário sul-africano anual: Dia da Liberdade (aniversário das primeiras eleições democráticas), Dia da Mulher (celebração da contribuição da mulher para a luta contra o apartheid), e Dia do Patrimônio Cultural. Os feriados fornecem conteúdos temáticos para as oficinas. No acampamento do Dia do Patrimônio Cultural, em que me concentro aqui, 60 crianças do $4^{\circ}$ ao $6^{\circ}$ ano do ensino fundamental participaram, sendo divididas em quatro grupos de 15 crianças cada. As oficinas são facilitadas pelo pessoal da NMI, bem como por uma equipe de voluntários recrutados, principalmente, entre os estudantes da Universidade de Fort Hare, que fica nas proximidades. Todos os facilitadores voluntários são apaixonados por escrever e por inspirar e apoiar as gerações mais jovens a se tornarem leitores e escritores, sendo alguns deles próprios poetas publicados e/ou artistas performáticos. Os professores das escolas desses alunos frequentam as sessões diárias, participando de atividades e apoiando os alunos nas sessões de redação individuais.

Embora as atividades e sessões específicas variem conforme o acampamento, elas seguem um padrão básico, no qual o primeiro dia começa com as crianças chegando cedo para o café da manhã e depois se reunindo em círculo para uma sessão de jogos, músicas e rimas. Os facilitadores se revezam entre si para conduzir músicas e jogos diferentes, alguns em isiXhosa, alguns em inglês, enquanto outros são híbridos, utilizando os recursos de ambas as línguas. Desde o início, o espaço Phemba Mfundi foi criado como um espaço bilíngue onde os recursos em isiXhosa e em inglês são valorizados e as crianças são posicionadas como bilíngues e biletradas. A última música/jogo envolve as crianças dividindo-as em quatro grupos para seguir seus facilitadores até os alojamentos. Músicas e jogos são usados, ao longo do dia, nos pequenos grupos para energizar as crianças, quando a atenção está diminuindo, e 
para injetar diversão e brincadeiras durante o dia. A sessão em pequenos grupos continua com apresentações individuais. Em seguida, sessões de contribuição sobre diferentes gêneros textuais, como narrativas pessoais, poesia e revisão de rascunhos são coordenadas em momentos diferentes. Elas são intercaladas com sessões individuais de redação, nas quais as crianças trabalham em pequenos grupos nas mesas e podem contar com a ajuda de facilitadores e professores. Essas sessões individuais de redação são seguidas por uma sessão comunitária, em que as crianças se voluntariam para ler o que escreveram ou para contar histórias e receber "feedback" de colegas e facilitadores. Todo o grupo de crianças se reúne em Jamboree em diferentes lugares do acampamento. Em um dos Jamboree, as crianças assistem às apresentações de poetas visitantes, contadores de histórias e músicos, e/ou apresentações de facilitadores voluntários. Outro tipo de Jamboree é realizado pelas próprias crianças. Nos grupos, as crianças preparam apresentações de suas poesias, histórias, poemas falados e peças de teatro para todo o grupo. Essas apresentações, assim como a publicação de textos selecionados na publicação Phemba Mfundi, garantem que as crianças tenham um público real para os textos que estão produzindo. Além das aulas expositivas dirigidas pelos facilitadores, vários recursos são disponibilizados para as crianças em todo o acampamento. Isto inclui uma série de fontes publicadas: histórias, livros ilustrados, biografias e antologias de poesia em inglês e isiXhosa, bem como dicionários bilíngues; anotações da oficina Phemba Mfundi, compiladas pelo NMI em um livreto para cada criança, incluindo orientações e exemplos sobre diferentes gêneros textuais e modelos de escrita; e anotações geradas de forma colaborativa durantes as sessões que são feitas pelos facilitadores e colocadas nas paredes ao redor dos diferentes locais para as crianças consultarem, como nas Figuras1 e 2 a seguir.

A valorização dos recursos tanto do isiXhosa quanto do inglês fica evidente na seleção e produção de materiais didáticos. Os livros publicados 
são disponibilizados em isiXhosa e inglês, e, às vezes, o mesmo livro está disponível nas duas línguas; as anotações dos alunos são bilíngues, a maioria das notas de instrução estão disponíveis em isiXhosa e inglês e com exemplos de texto em isiXhosa e em inglês fornecidos para cada um dos gêneros tratados nas anotações. As anotações produzidas de forma colaborativa pelos facilitadores e pelas crianças (ver Figuras 1 e 2) apresentam uma translinguagem entre isiXhosa e inglês, com os facilitadores tendendo a registrar as notas de acordo com a língua usados pela criança. Os próprios facilitadores movem-se perfeitamente entre os recursos de isiXhosa e inglês em suas conversas e as crianças são livres para utilizar seus repertórios linguísticos completos quando contribuem para as sessões da oficina, contando ou interpretando e escrevendo textos. O bilinguismo dinâmico e a translinguagem são, assim, modelados como a norma em textos falados, interpretados e escritos. Os exemplos de regras básicas geradas de forma colaborativa em um grupo (Figura 1) refletem este uso natural da linguagem com duas regras básicas geradas e registradas em inglês "No fighting" e "Respect each other"12 entre uma série de regras expressas em isiXhosa. Da mesma forma, o exemplo do painel na Figura 2, que registra as metas, "What are we doing here?" (Senzani Apha) e "What we did at the previous camp" (Izinto besisenza kwinkampu endlulileyo) ${ }^{13}$, utiliza recursos de isiXhosa e inglês sem separação rigorosa entre as línguas, como visto na Figura 2 "Sibukele ne film"/ We watched a movie ${ }^{14}$. O registro da translinguagem em texto escrito dessa forma modela para as crianças a legitimidade das práticas de uma linguagem fluida no espaço. Embora a translinguagem seja comum durante as conversas em sala de aula na África do Sul, é muito incomum ver isso por escrito no quadro.

\footnotetext{
12 "Não brigar" e "Respeitar uns aos outros"

13 "O que estamos fazendo aqui?" e "O que fizemos no acampamento anterior"

14 "Assistimos a um filme"
} 


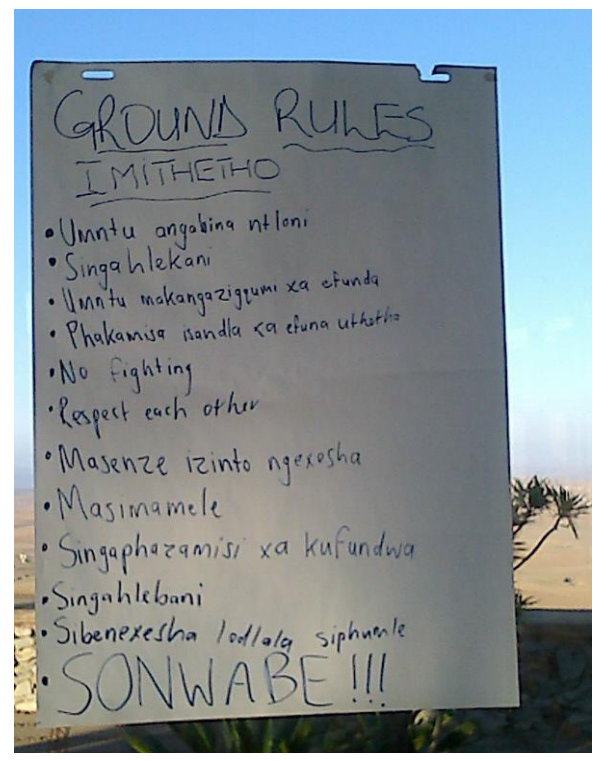

Figura 1; Fonte: elaboração própria. Tradução da Figura 7.1: “Ground rules"/Imithetho: Umntu angabina ntloni/Don't be shy; Singahlekakani/We don't laugh at each other; Umntu makangazigqumi xa efunda/ Don't cover yourself [hold the book to close to your face] when you read; Phakamisa isandla xa efuna uthetho/

Put your hand up when you want to talk; Masenze izinto ngexeshal Let's work within the given time; Masimamele/Let us listen; Singaphazamisi xa kufundwal Let's not disturb others when we are learning; Singahlebani/ We don't gossip about each other; Sibenexesha ladlala siphumle/we have time to play and rest; Sonwabe/

We must have fun!!!5

15 "Regras básicas"/ Não seja tímido / Não rimos um do outro / Não se cubra [segure o livro perto do rosto] ao ler / Levante a mão quando quiser falar / Vamos trabalhar dentro do prazo determinado/ Vamos ouvir/ Não vamos perturbar os outros quando estivermos aprendendo / Não fazemos fofocas uns sobre os outros / Temos tempo para brincar e descansar / Devemos nos divertir!! 


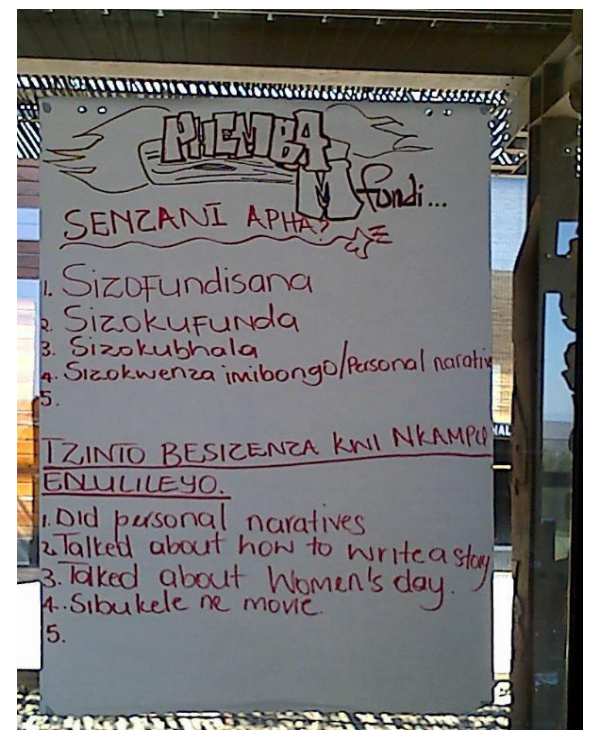

Figura 2; Fonte: elaboração própria

Concentro-me agora em descrever algumas das atividades específicas do acampamento do Dia do Patrimônio Cultural de setembro de 2014. Após as músicas e os jogos em círculos no pequeno grupo, o facilitador conduziu o grupo para as apresentações, pedindo a todos que se apresentassem e que nos falassem sobre seus nomes de clã. Esta atividade foi explicada e conduzida em isiXhosa com uma breve translinguagem em inglês. Por meio da própria apresentação do facilitador em isiXhosa, as crianças foram convidadas a valorizar suas famílias e sua língua de origem. O facilitador encerrou a sessão usando translinguagem entre inglês e isiXhosa, com uma mensagem final em inglês 'Obrigado, pessoal, por compartilharem coisas que não sabíamos sobre vocês. [Agora todos podemos sentir] "Este é o meu grupo e sou bem-vindo aqui". ' Seguindo as introduções do nome do clã, o facilitador iniciou a noção de 'herança' e conduziu uma discussão usando os recursos em isiXhosa e inglês. Outro dos facilitadores da NMI 
usa o tópico para chamar a atenção para a língua, e, neste caso, isiXhosa, como parte de sua herança: 'a língua vem à minha mente quando penso em minha herança' ('algo que valorizamos, algo que amamos' ). Esse é um raro momento em que a atenção é explicitamente direcionada para a língua nomeada, sendo usada como meio de comunicação. A facilitadora orienta as crianças a lerem em voz alta a versão em inglês do texto sobre 'Herança, cultura e identidade' em seus manuais. Ela justificou sua escolha do texto em inglês, explicando às crianças que muitas vezes elas não têm oportunidades suficientes para ler textos em inglês. Ela faz com que as crianças se revezem na leitura dos parágrafos do texto e, no final, pede que leiam a versão em isiXhosa silenciosamente para reforçar a mensagem. Há um posicionamento discursivo sutil aqui das crianças mais fluentes em isiXhosa do que em inglês.

Após uma sessão de escrita individual de poesia, com algumas crianças auxiliadas por facilitadores e professores na revisão dos rascunhos de seus poemas, a facilitadora, Mihlali, reuniu as crianças para uma sessão de feedback em grupo. Ela pôs duas versões do poema de uma criança em destaque no painel: um primeiro rascunho e um rascunho revisado, e pediu ao grupo que procurasse diferenças entre as duas versões e comentasse sobre a eficácia relativa das escolhas feitas pelo autor. $\mathrm{O}$ poema foi escrito em inglês e a própria Mihlali fala em inglês quando convida as crianças a responderem ao poema; a liberdade das crianças na escolha da língua em que devem responder fica, no entanto, clara, considerando o fato de que crianças diferentes fazem escolhas diferentes e não se chama a atenção para quais recursos linguísticos as crianças escolheram.

Após o almoço, as crianças foram presenteadas com uma sessão de Jamboree com duas apresentações dos convidados Zukiswa Wanner (autora) e Dineo Pule (músico). Wanner narrou sua releitura africana do conto Rapunzel, Refilwe, em inglês e Dineo Pule interpretou o segundo canto em isiXhosa e tocou o Uhadi (tradicional arco musical Xhosa feito 
de madeira, uma única corda e uma cabaça seca). O público foi então convidado a compartilhar suas histórias ou poemas. Uma criança contou duas histórias: a primeira em isiXhosa e a segunda em inglês. A história em inglês era sobre uma garota que deixou a África do Sul para ir aos Estados Unidos quando tinha cinco anos e aprendeu apenas inglês. $\mathrm{O}$ dilema apresentado é que, ao voltar para sua aldeia no Cabo Oriental, ela não consegue se comunicar com a avó e os primos em isiXhosa e se sente excluída. Embora o narrador use principalmente o inglês, ele é capaz de comunicar a exclusão da menina por meio do uso estratégico de isiXhosa, destacando as limitações dos recursos linguísticos da menina somente em inglês e sua exclusão. Notei que este tema também havia sido explorado anteriormente em um conto publicado na coleção editada da Phemba Mfundi, em 2014, na qual a experiência de uma criança que é escolarizada na única escola em inglês urbano da cidade, perde sua capacidade de falar isiXhosa e fica igualmente isolada de sua avó e das outras crianças ao voltar para a aldeia familiar. Essas histórias invertem os discursos que privilegiam exclusivamente o ensino médio inglês e o sonho de morar nos EUA. Eles fornecem evidências de que as crianças Phemba Mfundi estão internalizando os discursos contrários à anglonormatividade que circulam nos acampamentos de escritores. Suas apresentações e trabalhos escritos também fornecem provas do uso imaginativo de recursos linguísticos e de letramento, bem como outros modos de construção de significado.

Apesar da fluidez com que a translinguagem, utilizando isiXhosa e inglês, é usada nas discussões orais, jogos, canções e aulas expositivas nas oficinas, as crianças tendiam a escrever seus poemas e histórias em uma única língua, seja inglês ou isiXhosa. A mesma criança pode escolher escrever um poema em inglês e uma narrativa em isiXhosa ou vice-versa. No final do ano, quando as crianças são encorajadas a enviar seus escritos para inclusão na revista anual Phemba Mfundi, publicada pelo NMI, elas são solicitadas a enviar pelo menos um texto em isiXhosa e um em inglês, 
embora possam enviar mais. A revista publicada segue uma abordagem bilíngue semelhante ao manual ou notas do acampamento, em que seções são rotuladas e temas introduzidos em ambas as línguas, muitas vezes sendo paralelos um ao outro, em uma coluna à esquerda e à direita ao longo da página. A própria escrita criativa é reproduzida na língua em que é escrita, sendo assim, apenas o texto editorial é incluído em duas línguas. Isso é significativo por duas razões. Em primeiro lugar, embora a translinguagem ou a utilização fluida dos recursos de isiXhosa e do inglês seja a norma em discursos falados, escritos e multimodais durante as sessões conjuntas no acampamento, isso não significa que as crianças e os facilitadores não possam produzir textos em uma única língua quando eles o desejam ou são obrigados a fazê-lo. Não há dúvida de que, para essas crianças, isiXhosa é sua língua dominante, embora elas estejam se tornando bilíngues e biletradas com sucesso em inglês e isiXhosa por meio da iniciação em práticas de translinguagem nos acampamentos de produção escrita.

Ao reposicionar as crianças como imaginativas, entusiastas e capazes de criar significados, os acampamentos Phemba Mfundi ilustram a pedagogia transgressiva de várias maneiras. Facilitadores bilíngues altamente proficientes constantemente provocam a ideologia monoglóssica, que mantém as línguas em silos separados, na medida em que modelam a translinguagem por meio do uso espontâneo, e às vezes deliberado, de todos os recursos de seus repertórios linguísticos. O fato de que, na maioria das vezes, a atenção não é voltada para as línguas nomeadas, significa que a translinguagem é construída como uma prática linguística normativa neste contexto. A falta de atenção às línguas nomeadas e a falta de julgamento do uso da língua das crianças significa que essas crianças podem correr riscos no uso do inglês como bilíngues emergentes. Fiquei impressionada com o exemplo de um menino que sempre optou por fazer suas contribuições em inglês, apesar do fato de que teria sido mais fácil para ele falar em isiXhosa. Outras crianças contribuíram, com mais frequência, oralmente em 
isiXhosa, mas produziram textos escritos em inglês. A liberdade de escolha em relação aos recursos linguísticos permitiu que as crianças exercessem seu livre-arbítrio nos acampamentos de produção escrita. Os discursos sobre a língua, que são produzidos nas discussões, criticam ainda mais a anglonormatividade ao valorizar abertamente o isiXhosa tanto como um recurso atual quanto como uma parte significativa da herança das crianças. As próprias crianças reproduzem esses discursos em suas próprias escritas e performances, destacando a inadequação de outras que são monolíngues em inglês.

\section{Conclusão}

Este capítulo chamou a atenção para a orientação monolíngue do atual currículo e política linguística sul-africana, conforme é implementado nas escolas. Argumentei que o currículo e a política reforçam a anglonormatividade, ignorando os recursos linguísticos da maioria das crianças sul-africanas. $\mathrm{O}$ fornecimento exclusivo de materiais de aprendizagem monolíngues, avaliações e currículo em inglês não só contraria o direito constitucional das crianças de receberem educação em suas línguas familiares, mas também ignora as formas heteroglóssicas em que a língua é usada na vida diária e a extensa literatura de pesquisa sobre as dinâmicas abordagens bilíngues de ensino e aprendizagem. A língua na educação é, portanto, um espaço no qual a longa sombra da colonialidade (e de seu apartheid) é lançada com consequências desastrosas para as crianças de língua africana e para os falantes de variedades não-padronizadas. Não há dúvida de que é urgente uma revisão da desatualizada Política de Línguas em Educação de 1997 e da oferta de línguas no currículo atual.

No entanto, ocorrendo fora da escola formal, o espaço de aprendizagem e criação do clube de escrita Phemba Mfundi não é moldado e limitado pelas ideologias da linguagem colonial que saturam o sistema 
escolar. Os alunos não estão restritos ao uso de apenas uma língua nomeada por vez e à valorização exclusiva do inglês como língua europeia. Embora a construção da língua nomeada isiXhosa, reconhecida como uma das 11 línguas oficiais da constituição, possa ser vista como produto de intervenção missionária e, portanto, uma construção colonial, ela foi apropriada como um recurso pelas crianças para projetar seus próprios significados fora das restrições da anglonormatividade e dos modos coloniais impostos de conhecer e ser. Ao contrário das salas de aula da escola, não se espera que as crianças operem em uma língua (como se fossem monolíngues), mas que possam recorrer a seus repertórios linguísticos e semióticos completos. Os materiais escritos são produzidos bilinguamente, mostrando às crianças como o conhecimento pode ser feito e compartilhado por meio dos recursos linguísticos de sua ancestralidade e não, exclusivamente, através do inglês e outras línguas europeias. As crianças do Phemba Mfundi (Aprendizes do fogo) acendem uma centelha de esperança de que podemos trabalhar contra a colonialidade e abraçar a heteroglossia na pedagogia da linguagem e do letramento nas escolas sul-africanas e em outras partes do mundo.

[1] Anglonormatividade baseia-se na noção feminista-pós-estruturalista de heteronormatividade que coloca em primeiro plano a normatividade institucionalizada da heterossexualidade e as consequências negativas de longo alcance para aqueles que não se identificam como heterossexuais.

[2] Destaca-se nesta literatura a falta de um plano de implementação da política; o fato de o novo currículo nacional ter sido desenvolvido separadamente da política linguística, indicando, assim, uma falta de vontade política para promover o multilinguismo; bem como a percepção comum entre os pais de que as crianças só desenvolverão proficiência avançada em inglês se o usarem como meio de instrução (ver Banda, 2000; De Klerk, 2002; Heugh, 2013; Plüddeman, 2015; Probyn et al ., 2002, 2005).

[3] O modelo de saída precoce refere-se ao uso do ensino da língua inicial nos primeiros anos de escolaridade (1-3 anos), com saída antecipada 
para o ensino da língua inglesa posteriormente; O modelo de transição repentina refere-se a uma mudança repentina na linguagem de ensino de um ano para o outro (ver Walter, 2008).

[4] Segundo Bakhtin (1981), a heteroglossia pode ser definida como o uso complexo e simultâneo de uma gama diversificada de registros, vozes, línguas ou códigos, em nossa vida diária, mas também chama a atenção para a tensão potencial entre diferentes tipos de registros e vozes. (Ivanov, 2000, ver também Bailey, 2007).

[5] Ver Brutt Griffler (2002) sobre o uso da língua materna como meio de instrução, a fim de restringir o acesso ao inglês nas colônias britânicas do Lesoto e Sri Lanka.

\section{Referências}

AG, Astrid; JORGENSON, Jens Normann. Ideologies, norms, and practices in youth poly-languaging. International Journal of Bilingualism. 17(4) p. 525-539, 2013.

ANZALDUA, Gloria. Borderlands/La Frontera: The New Mestiza. USA: Aunt Lute Books, 1987.

BAILEY, Benjamin. Heteroglossia and boundaries. In: HELLER, Monica (Org.) Bilingualism: A Social Approach. Palgrave Macmillan, 2007.

BAKHTIN, Mikhail Mikhailovich. Discourse in the Novel, in HOLQUIST, Michael (Org.) The Dialogic Imagination four essays, Austin: University of Texas Press. (translated by C. Emerson and M. Holquist), 1981.

BLACKLEDGE, Adrian; CREESE, Angela. Translanguaging and the Body, International Journal of Multilingualism, 14 (3): 250-268, 2017.

BLOMMAERT, Jam. Language Ideology. In: BROWN, Keith (Editor-inChief) Encyclopedia of Language \& Linguistics, Second Edition, volume 6, p. 510-522. Oxford: Elsevier, 2006. 
BRUTT-GRIFFLER, Janina. Class, Ethnicity and Languaeg Rights: An Analysis of British Colonial Policy in Lesotho, Sri Lanka and some implications for language policy. Journal of Language Identity and Education 1(3) p. 207-234, 2002.

FREDERICKS, Ilse; DAN, Zodidi. Not allowed to speak Xhosa, Cape Times, África do Sul, 2 Set. 2017, page 1.

CREESE, Angela; BLACKLEDGE, Adrian., Translanguaging in the bilingual classroom: A pedagogy for learning and teaching? The Modern Language Journal, 94(1), p.103-115, 2010.

DE KLERK, Gerda. Mother tongue education in South Africa: the weight of history. International Journal of the Sociology of Language 154, p. 29-46, 2002.

Department of Education. Language in education policy, 14 July 1997. Pretoria: Department of Education, 1997.

Department of Basic Education (DBE). The status of the language of learning and teaching (LOLT) in South African Public Schools: A Quantitative Overview. Pretoria: DBE, 2010.

GARCIA, Ofelia; WEI, Li. Translanguaging: Language, Bilingualism and Education. Palgrave Macmillan, 2014.

GUZULA, Xolisa; MCKINNEY, Carolyn; TYLER, Robyn. Languaging-forlearning: legitimising translanguaging and enabling multimodal practices in third spaces. Southern African Linguistics and Applied Language Studies 34, p. 211-226, 2016.

HEUGH, Kathleen. Multilingual Education Policy in South Africa Constrained by Theoretical and Historical Disconnections. Annual Review 
of Applied Linguistics. 33, p. 215-237, 2013.

IVANOV, Vyacheslav. Heterglossia. Journal of Linguistic Anthropology. 9(12). p. 100-102, 2000.

KAMWANGAMALU, Nkonko. One language, multi-layered identities: English in a society in transition, South Africa. World Englishes 26(3) p. 263-275, 2007.

MAKALELA, Leketi. Translanguaging as a vehicle for epistemic access: cases for reading comprehension and multilingual interactions. Per linguam, 31(3), p. 15-29, 2015.

MAKONI, Sinfree. African languages as Colonial scripts. In: COETZEE, Carli; NUTTALL, Sarah (org.). Negotiating the Past. Cape Town: Oxford University Press, 1999.

MAKONI, Sinfree; MEINHOF, Ulrike. Introducing Applied Linguistics in Africa. AILA Review, 16, p. 1-12. 2003

MAKONI, Sinfree, MAKONI, Busi; ROSENBERG, Aaron. The Wordy Worlds of Popular Music in Eastern and Southern Africa: Possible Implications for Language-in-Education-Policy. Journal of Language, Identity and Education 9(1) p. 1-16, 2010.

MALDONADO, Nelson. On the coloniality of being: Contributions to the development of a concept. Cultural Studies, 21(2-3), 240. 2007

MARTIN-JONES, Marilyn. Bilingualism, education and the regulation of access to language resources. In: HELLER, Monica (Ed) Bilingualism: A social approach, Basingstoke and New York: Palgrave Macmillan. 2007.

MCKINNEY, Carolyn. Moving between ekasi and the suburbs: The 
mobility of linguistic resources in a South African de(re)segregated school. In: PRINSLOO, Mastin; STROUD, Chris (Org.) Educating for Language and Literacy Diversity. Basingstoke, U.K.: Palgrave MacMillan. 2014. p. 97115.

MCKINNEY, Carolyn. Language and Power in Post-colonial schooling: Ideologies in Practice. New York and London: Routledge, 2017.

NGŨGI WA THIONGO. Decolonising the Mind: The Politics of Language in African Literature. London: James Currey, 1986.

PLÜDDEMAN, Peter. Unlocking the grid: language in education policy realisation in post-apartheid South Africa. Language and Education 29(3), p. 186-199, 2015.

PROBYN, Margie. Pedagogical translanguaging: bridging discourses in South African science classrooms, Language and Education 29(3) p. 218$234,2015$.

SEBBA, Mark. What is 'mother tongue'? : Some problems posed by London Jamaican. In: ACTON, Thomas; DALPHINIS. Morgan (Org.) Language Blacks and Gypsies Languages without a written tradition and their role in education. London: Whiting and Birch, 2000, p. 109-121.

PROBYN, Margie. Language and the struggle to learn: the intersection of classroom realities, language policy, and neo-colonial and globalisation discourses in South African schools. In: LIN, Angel; MARTIN, Peter. (Org.) Decolonisation, Globalisation Language-in-Education Policy and Practice. Clevedon: Multilingual Matters Ltd, 2005.

PROBYN, Margie; MURRAY, Sarah; BOTHA, Liz; BOTYA, Paula, BROOKS, M; WESTPHAL, Vivian. Minding the gaps - an investigation 
into language policy and practice in four Eastern Cape Districts. Perspectives in Education 20(1), p. 29-46, 2001.

UNESCO. The Use of Vernacular Languages in Education. Paris: UNESCO, 1953.

UNESCO. Education in a multilingual World UNESCO Education Position Paper. Paris: UNESCO, 2003.

WALTER, S.. The Language of instruction issue: Framing an empirical perspective. In Spolsky, B and Hult, F. (Eds) The Handbook of Educational Linguistics, Malden, Blackwells, 2008. p. 129-146.

WINKLER, G. The Myth of the Mother Tongue: Evidence from Maryvale College, Johannesburg. South African Journal of Applied Language Studies 5(1), p. 29-39, 1997.

Decoloniality and language in education: Transgressing language boundaries in South Africa

\section{ABSTRACT}

This chapter draws on theories of Decoloniality to show how language in education policy in South Africa continues to be shaped within a 'colonial matrix of power' (Mignolo, 2009). This leads to the silencing of African children and their exclusion from access to quality education. The chapter argues that transgressing socially constructed language boundaries and disrupting monolingual language ideologies is central to the repositioning of language as a resource for learning in South African schooling. The first part of the chapter provides an analysis of the language ideologies underpinning language in education policies and curricula in South Africa. The analysis will show how Anglonormativity (the expectation that people are or should be proficient in English and are positioned as deficient, even deviant if they are not) and monolingualist ideologies shape the current implementation of language policy in South African Schools. The second part of the chapter presents a case-study of decolonial language and literacy pedagogy that transgresses language boundaries enabling children to draw on their full 
linguistic repertoires as resources for meaning-making. Keywords: Anglonormativity. Linguistic ideology. Translanguage. South Africa.

Recebido em: 30/11/2021

Aceito em: 06/04/2021 


\section{Varia}

Multilinguismo, discurso e direitos linguísticos 